\title{
O capital humano nas organizações da sociedade do conhecimento e o agir da comunicação na preservação da identidade humana.
}

\author{
Prof. Ms.C. Sônia Grácia Pucci Medina \\ Universidade Veiga de Almeida - Rio de Janeiro \\ Doutoranda em Psicologia Social \\ Universidad John Kennedy em Buenos Aires \\ sonia@soniapucci.com
}

(Recibido 27/8. Aceptado 18/11/2014)

\section{Resumo}

Estamos no amanhecer da compreensão de nosso lugar no universo e dos espetaculares poderes latentes que possuímos, quais sejam a flexibilidade e a transcendência de que somos capazes.

Sendo a globalização um novo elemento ambiental, é necessário observar como as estratégias, estão gerando mudanças na estrutura organizacional e no comportamento do indivíduo, descaracterizando sua identidade e subjetividade.

O novo ambiente sócio técnico deve contemplar a configuração do conjunto de recursos tecnológicos, recursos humanos, e os recursos de infraestrutura. O nível de integração deste conjunto de recursos é fundamental para que seja possível e viável técnica e financeiramente a adoção de equipes multi e poli funcionais para que o engajamento proativo do corpo de funcionários seja o elemento vital para o sucesso de uma empresa.

Palavras-chave: capital humano, labor, sociedade do conhecimento, agir, comunicação.

\section{Human capital in the knowledge society organizations and the act of communication in the preservation of hu- man identity}

\begin{abstract}
We are at the dawn of understanding of our place in the universe and spectacular latent powers we possess, namely flexibility and transcendence that we are able.

As globalization a new environmental element, it is necessary to observe how the strategies are generating changes in the organizational structure and the individual's behavior, debased their identity and subjectivity.

The new technical partner environment must contemplate the set of technological resources configuration, human resources, and infrastructure resources. The level of integration of this set of resources is essential for to be possible and feasible from a technical and financial viewpoint, adopting multi and poly functional teams and proactive engagement of officials, are vital to the success of a company.
\end{abstract}

Keywords: human capital, labor, knowledge society, communication. 


\section{I - Introdução:}

Estamos no amanhecer da compreensão de nosso lugar no universo e dos espetaculares poderes latentes que possuímos, quais sejam a flexibilidade e a transcendência de que somos capazes.

O labor se constitui como principal eixo para a continuidade e sobrevivência da espécie humana. Ao propor este ensaio sobre $O$ trabalho na visão de Hanna Arendt (2007) em A condição Humana como um dos fundamentos do projeto de tese sobre O capital humano nas organizações da sociedade do conhecimento e o agir da comunicação, temos que iniciar conceituando a relação entre labor, trabalho e ação, para a existência da vida ativa.

\section{II - Conceito entre labor, trabalho e ação.}

O labor é um processo de ordem biológica do corpo, cujo desenvolvimento e insucesso estão relacionados com as necessidades essenciais inseridas no processo da vida.

O trabalho faz parte do universo produtivo de coisas e objetos, diferentes do ambiente natural. O produto do trabalho são os artefatos e é norteado pelo fim do produto, no qual vai exigir habilidades e competências para suprir as necessidades da subsistência da vida humana.

Arendt (2007) conceitua ação como uma atividade política. A ação, única atividade que se exerce diretamente entre os homens sem a mediação das coisas ou da matéria, corresponde, à condição humana da pluralidade, ao fato de que homens, e não Homem vive na Terra e habitam o mundo. Todos os aspectos da condição humana têm alguma relação com a política; mas esta pluralidade é especificamente a condição da vida política.

A ação seria um luxo desnecessário, uma caprichosa interferência com as leis gerais de comportamento, se os homens não passassem de repetições interminavelmente reproduzíveis do mesmo modelo, todas dotadas da mesma natureza e essência, tão previsíveis quanto a natureza e a essência de qualquer outra coisa.

A pluralidade é a condição da ação humana pelo fato de sermos todos os mesmos, isto é, como coloca Arendt: "humanos, sem que ninguém seja exatamente igual a qualquer pessoa que tenha existido, exista ou venha a existir".

As atividades humanas e suas respectivas condições têm íntimas relações com as condições mais gerais da existência humana: o nascimento e a morte, a natalidade e a mortalidade.

O labor garante não apenas a sobrevivência do indivíduo, mas a vida da espécie. O trabalho e seu produto, o artefato humano, emprestam certa permanência e durabilidade à fertilidade da vida mortal e ao caráter efêmero do tempo humano (Arendt). A ação, na medida em que se empenha em fundar e preservar corpos políticos cria a condição para a lembrança, ou seja, para a história. O labor e o trabalho, bem como a ação, têm também raízes na natalidade, na medida em que sua tarefa é produzir e preservar o mundo para o constante influxo de recém-chegados que vêm a este mundo na qualidade de estranhos.

Das três atividades - ação, labor e trabalho - a ação é a mais intimamente relacionada com a condição humana da natalidade; o novo começo inerente a cada nascimento pode fazer-se sentir no mundo somente porque o recém-chegado possui capacidade de iniciar algo novo, isto é, de agir. Arendt relata que neste sentido de iniciativa, todas as atividades humanas possuem um elemento de ação e, portanto, de natalidade. A condição humana deve ser compreendida como algo mais que as condições nas quais a vida foi dada ao homem. $O$ mundo no qual transcorre a vida ativa consiste em coisas produzidas pelas atividades humanas; mas, constantemente, as coisas que devem sua existência exclusivamente aos homens também condiciona seus autores humanos. Além das condições nas quais a vida é dada ao homem na Terra e, até certo ponto, a partir delas, os homens constantemente criam as suas próprias condições que, a despeito de sua variabilidade e sua origem humana, possuem a mesma força condicionante das coisas naturais. O que quer que toque a vida humana ou entre em duradoura relação com ela, assume, de forma imediata, o caráter de condição da existência humana. É por isso, para Arendt que os homens, independentemente do que façam, são sempre seres condicionados. 
Para evitar erros de interpretação, Arendt indica que: a condição humana não é o mesmo que a natureza humana, e a soma total das atividades e capacidades humanas que correspondem à condição humana não constitui algo que se assemelhe à natureza humana. Pois nem o pensamento e a razão, e nem mesmo a mais meticulosa enumeração de todas elas, constituem características essenciais da existência humana no sentido de que, sem elas, essa existência deixaria de ser humana.

\section{III - Sociedades em mudança.}

Isso é evidente mesmo em bebes recém-nascidos, que pesquisas revelaram ser incrivelmente sensíveis, buscando padrões, reagindo a emoções sutis na voz humana, sendo atraídos por rostos e discriminando cores. Mas a ciência demonstrou também com que facilidade os bebes recém-nascidos podem ser programados e condicionados a responder a uma luz ou campainha, de forma semelhante a dos cães que salivavam nas famosas experiências de Pavlov. Tanto Teilhard de Chardin (2001) quanto Skinner (2003) estavam certos: somos capazes de saltos evolucionários e de condicionamentos em compartimentos.

Só se pode ter uma nova sociedade, se for modificada a educação da geração mais jovem. Contudo, a nova sociedade é a força necessária para a mudança.

A primeira vista, porém, é surpreendente que a era moderna - tendo invertido todas as tradições, tanto a posição tradicional da ação e da contemplação como a tradicional hierarquia dentro da própria vida ativa, tendo glorificado o labor (trabalho) como fonte de todos os valores - não tenha produzido uma única teoria que distinguisse claramente entre 'o labor do nosso corpo e o trabalho de nossas mãos' (Arendt, 2007).

Ao invés disso, encontra-se primeiro, a distinção entre trabalho produtivo e improdutivo; um pouco mais tarde, a diferenciação entre trabalho qualificado e não qualificado; e, finalmente, sobrepondo-se a ambas por ser aparentemente de importância mais fundamental, a divisão de todas as atividades em trabalho manual e intelectual. Das três, porém, Arendt revela que somente a distinção entre trabalho produtivo e improdutivo vai ao fundo da questão; e não foi por acaso que os dois grandes teoristas do assunto, Adam Smith e Karl Marx, basearam nela toda a estrutura do seu argumento.

O próprio motivo da promoção do labor como trabalho na era moderna foi a sua 'produtividade'; e a noção aparentemente blasfema de Marx de que o trabalho (e não Deus) criou o homem, ou de que o trabalho (e não a razão) distingue o homem dos outros animais, era apenas a formulação mais radical e coerente de algo com que toda a era moderna concordava. Além do mais, tanto Smith quanto Marx estava de acordo com a moderna opinião pública quando menosprezava o trabalho improdutivo, que para eles era parasítico, uma espécie de perversão do trabalho, como se fosse indigno deste nome toda atividade que não enriquecesse o mundo (Arendt).

Em outras palavras, a distinção entre trabalho produtivo e improdutivo contém, embora eivada de preconceito, a distinção mais fundamental entre trabalho e labor. Aqui, deve-se atentar que a distinção entre trabalho produtivo e improdutivo se deve aos fisiocratas, que diferenciavam entre classes produtoras, proprietários e estéreis. Como afirmavam que a fonte original de toda produtividade residia nas forças naturais da terra, o critério de produtividade que adotavam tinha a ver com a criação de novos objetos, e não com as necessidades e desejos dos homens. Realmente é típico de todo labor nada deixar atrás de si: o resultado do seu esforço é consumido quase tão depressa quanto o esforço é dependido. E, no entanto, esse esforço, a despeito de sua futilidade, decorre de enorme premência; motiva-o um impulso mais poderoso que qualquer outro, pois a própria vida depende dele.

Essa produtividade, para Arendt não reside em qualquer um dos produtos do labor, mas na 'força' humana, cuja intensidade não se esgota depois que ela produz os meios de sua subsistência e sobrevivência, mas é capaz de produzir um 'excedente', ou seja, mais que o necessário à sua 'reprodução'. Uma vez que não é o próprio trabalho, mas o excedente da 'força' de 'trabalho' humana, que explica a produtividade do trabalho e, como a sua força não se extingue quando a própria reprodução já está assegurada, pode ser utilizada para a reprodução de mais de um processo vital, mas nunca 'produz' outra coisa senão ‘vida' (Arendt).

Mediante violenta opressão numa sociedade de escravos, ou mediante a exploração na sociedade capitalista da época de Marx, pode ser canalizada de tal forma que o labor de alguns é bastante para a vida de todos. Deste ponto de vista puramente social, que é o ponto de vista de toda a era moderna, mas que recebeu sua mais 
coerente e grandiosa expressão na obra de Marx, todo trabalho é 'produtivo'; e perde sua validade a distinção anterior entre a realização de 'tarefas servis', que não deixam vestígios, e a produção de coisas suficientemente duráveis para que sejam acumuladas.

Como se notou, o ponto de vista social é idêntico à interpretação que nada leva em conta a não ser o processo vital da humanidade; e, dentro de seu sistema de referência, todas as coisas tornam-se objetos de consumo. Numa sociedade complementar 'socializada', cuja única finalidade fosse a sustentação do processo vital - e é este o ideal, infelizmente um tanto utópico, que orienta as teorias de Marx - a distinção entre labor e trabalho desapareceria completamente; todo trabalho tornar-se-ia labor, uma vez que todas as coisas seriam concebidas, não em sua qualidade mundana e objetiva, mas como resultados da força viva do labor, como funções do processo vital.

\section{IV - Novos paradigmas.}

Alvin Toffler, em A terceira onda (1976) diz que a sociedade é uma reunião de fatores muito complexos no qual devem necessariamente conviver fatores de origem e conteúdo diferentes: econômicos, psicológicos, políticos, culturais, entre outros, sendo a um tempo estáveis e mutáveis seu arranjo e seu devir histórico. Assim, não é possível reduzir a complexidade social a fatores únicos determinantes.

A luta de classes, as relações de produção, a economia predominante, a cultura hegemônica e a subalterna, as expectativas e ambições dos indivíduos ou dos grupos, são fatores relevantes, porque fortemente interativos, coexistem no interior de cada época histórica e determina sua configuração, seu arranjo e o seu equilíbrio.

A análise da mudança deve forçosamente levar em consideração todos esses aspectos múltiplos e variáveis, uma vez que seria impossível compreender a dinâmica da mudança partindo de um único fator ou de apenas um grupo de fatores. É preciso, pelo contrário, compreender seu conjunto, o todo, o arranjo social e que ao mesmo tempo contém os elementos de superação.

A economia mundial passa por uma grande transformação que se manifesta tanto na base produtiva quanto nos âmbitos financeiro e político. Essas mudanças têm se refletido sobre os diversos mercados e estão associados à emergência da denominada Terceira Revolução Industrial; à formação de blocos econômicos, ao grande aumento do volume de recursos transacionados no sistema financeiro internacional e ao fortalecimento do liberalismo como a expressão política desse novo processo.

O fenômeno da globalização está presente e parece irreversível. No aspecto organizacional, ele se manifesta na internacionalização das empresas, o que provoca mudança interna em diversos níveis (Rhinesmith, 1993; Bartlett e Ghoshal, 1992).

Parece necessário fazê-las avançar, com o estudo das mudanças organizacionais ocorridas a partir da adoção de estratégias internacionais referentes à importância do capital humano. (Fernandes, 1996).

Desde Max Weber (1946), a teoria das organizações vem concentrando esforços na compreensão do fenômeno organizacional. O estudo das estruturas foi destaque durante as décadas de 6o e 70. A partir daí, enfatizaramse as considerações sobre o ambiente organizacional. As organizações passam a ser percebidas como sistemas abertos que realizam trocas com o ambiente externo, sendo, portanto, suscetíveis de mudanças.

Após a Segunda Guerra Mundial, a nova ordem econômica internacional diminuiu barreiras comerciais, favoreceu a cooperação entre países e o estabelecimento de acordos de comércio. Essa nova disposição incrementou sobremaneira as trocas internacionais (Williamson, 1989), ampliando as atividades organizacionais. A expansão do comércio mundial levou à internacionalização das empresas não só em termos de expansão de mercados, mas também da exportação de modelos de gestão, tecnologia e estruturas organizacionais (Fajnzber, 1983).

O ambiente das organizações se ampliou e, na literatura especializada, passou-se a analisar esse fenômeno incorporado a noção de sistemas abertos com ênfase em processos de mudanças. Com os estudos ambientais, os pesquisadores organizacionais preocuparam-se em entender o trinômio ambiente-estratégia-estrutura (Melin, 1992).

As empresas, para aumentarem sua competitividade e conquistarem novos mercados, têm efetuado uma ampla reformulação das suas estruturas produtivas visando reduzir custos e melhorar a qualidade dos produtos. 
Isto implica na substituição dos princípios fordistas de produção, baseadas na rígida divisão do trabalho na prescrição individual de tarefas e na falta de autonomia dos operários na definição dos métodos de trabalho por novos princípios pautados na flexibilidade e pela capacidade de oferecer respostas rápidas e eficientes em contextos marcados pela mudança e pela incerteza.

O novo paradigma produtivo, conhecido como aprendizado flexível, apresenta três características: a primeira são as inovações tecnológicas. Na raiz do processo de globalização está o que alguns autores vêm chamando de novo paradigma tecnológico (Nakano, 1994). A revolução microeletrônica deu origem a novas tecnologias nas áreas da informática, telecomunicações, materiais, biotecnologia, lazer, entre outros, que vêm provocando mudanças no sistema produtivo mundial, na estrutura das organizações e no próprio comportamento humano. Estas descobertas possibilitam um grande aumento da produtividade e uma maior flexibilidade dos processos produtivos.

A segunda característica é expressa pela mudança de soluções entre as empresas, onde se dissemina a prática da terceirização, que consiste na tentativa de concentrar esforços naquelas atividades sobre as quais a empresa deterá evidentes vantagens competitivas, desmembrando parte de suas outras atividades e passando a adquirir serviços e insumos de outras empresas.

A última refere-se ao advento de novos processos organizacionais na produção e no trabalho interno das empresas que objetivam o aumento da eficiência. Para isso, tem-se procurado diminuir os níveis hierárquicos como forma de agilizar a tomada de decisão por meio, de uma maior coordenação interna entre as várias áreas e departamentos.

Isto tem possibilitado a maior participação do trabalhador na gestão do processo de produção, e exige-se do capital humano aptidão para trabalhar em equipe, para adaptar-se a mudanças no tipo de atividade que irá desempenhar, para exercer liderança.

A divisão do labor é, segundo Arendt, realmente, resultado direto do processo de labor, e não deve ser confundido com o princípio, aparentemente semelhante, da especialização que prevalece nos processos de trabalho e com o qual não deve ser equacionada. A especialização do trabalho e a divisão do labor têm em comum somente o princípio geral da organização, princípio este que, em si, nada tem a ver com o trabalho ou o labor, mas deve sua origem à esfera de vida estritamente política, ao fato de que o homem é capaz de agir, e de agir na companhia e em acordo com os outros. Somente dentro da estrutura da organização política, onde os homens não apenas vivem, mas agem juntos, podem ocorrer a especialização do trabalho e a divisão do labor.

Contudo, cabe enfatizar que, enquanto a especialização do trabalho é essencialmente guiada pelo próprio produto acabado, cuja natureza é exigir diferentes habilidades que, em seguida, são reunidas e organizadas em um conjunto, a divisão do labor, pelo contrário, pressupõe a equivalência qualitativa de todas as atividades isoladas para as quais nenhuma qualificação é necessária; e estas atividades não têm uma finalidade em si mesma, mas representam somente quantidades laborativas.

A revolução industrial substituiu todo artesanato pelo labor; o resultado foi, para Arendt, que as coisas do mundo moderno se tornaram produtos do labor, cujo destino natural é serem consumidos, ao invés de produtos do trabalho, que se destinam a ser usados.

A divisão do labor, e não um aumento de mecanização substitui a rigorosa especialização antes exigida para todo o tipo de artesanato. O artesanato, na visão de Arendt, é necessário somente para o projeto e fabrico do modelo, antes que este seja produzido em massa, o que também depende de máquinas e ferramentas. Mas a produção em massa seria, além disso, completamente impossível sem a substituição de trabalhadores e da especialização por operários e pela divisão do labor.

O caso é diferente na transformação moderna do processo do trabalho pela introdução do princípio da divisão do trabalho. Neste caso, Arendt explica que a própria natureza do trabalho é alterada e o processo de produção, embora não produza absolutamente objetos para o consumo, assume caráter de labor. Embora as máquinas tenham levado a um ritmo infinitamente mais rápido de repetição que aquele prescrito pelo ciclo dos processos naturais - e é bem possível que esta aceleração especificamente moderna faça ignorar o caráter repetitivo de todo labor - a repetição e a interminabilidade do próprio processo imprimem-lhe a marca inconfundível do labor. Isto se torna ainda mais claro nos objetos de uso produzidos por essas técnicas de trabalho. Vive-se em uma sociedade de operários, porque somente o labor, com sua inerente fertilidade, tem possibilida- 
de de produzir a abundância; e transforma-se o trabalho em labor, separando-o em partículas minúsculas até que ele se prestou à divisão, na qual o denominador comum da execução mais simples é atingido para eliminar do caminho do labor humano - que é parte da natureza e talvez a mais poderosa de todas as forças naturais - o obstáculo da estabilidade inatural e puram||ente do artifício humano.

\section{V - Proposta conclusiva.}

Este trabalho se justifica no sentido de contribuir na determinação das possíveis razões do fazer, o que significa desvendar sua racionalidade intrínseca. Um modelo de racionalidade configura certo paradigma filosófico predominante numa época. A expressão paradigma não é usada em seu sentido estrito, como modelo de ciência historicamente situado numa determinada área do conhecimento, mas em seu sentido mais amplo, como conjunto de pressupostos que estruturam e condicionam o pensamento de toda uma época.

Limitar a pesquisa ao primeiro nível de mudanças parece interessante, uma vez que o processo de mudanças na área de recursos humanos é relativamente recente; mas, as mudanças em relação a fisiologia de uma empresa é essencial, pois neste aspecto se situa o Capital Humano como elemento estratégico numa organização. Rio de Janeiro / junho / 2014.

\section{Referencias bibliográficas:}

Arendt, Hannah. (2007) A Condição Humana. Trad. Roberto Raposo, posfácio de Celso Lafer. Rio de Janeiro: Forense Universitária.

Bartlett, C.\& Ghoshal, S.(1992) Gerenciando empresas no exterior: a solução transnacional. São Paulo. Makron Books.

Fajnzylber, F. (1983) La industrialização trunca de América Latina. México: Editorial Nueva Imagen.

Medina, S.G.P. (2007) Incongruências: uma nova forma de ensinar no século XXI. São Paulo, Ed. Horizonte.

Melin, L. (1992) Internacionalization as a strategy process. Strategic Management Journal 3. New York. 99-118.

Nakano, Y. (1994) Globalização, competitividade e novas regras de comércio mundial. Revista Economia Política 14.4 (56) out.-dez. 7-30.

Rhinesmith, S. H. (1993) Guia gerencial para a globalização: seis chaves para o sucesso num mundo em transformação. Rio de Janeiro: Berkeley.

Skinner, B.F. (2003) Ciencia e Comportamento Humano. São Paulo: Martins Fontes.

Teilhard de Chardin, P. (2001) Fenómeno Humano. São Paulo: Cultrix.

Toffler, A. (1993) A terceira onda. Trad. João Távora. Rio de Janeiro: Record.

Weber, M. (1947) The theory of social and economic organization. NewYork: Free Press.

Williamson, J. (1983) A Economia aberta e a economia mundial. Rio de Janeiro: Campus. 